\title{
Experimental Investigation for The Flow Induced Vibration for Pipe Inside Water
}

\author{
Haitham Mohsin Salman ${ }^{1}$, Ansam Adel Mohammed ${ }^{2 *}$
}

\section{Authors affiliations: \\ 1) Mechanical Eng. Dept., Al- Nahrian University, Baghdad, Iraq. haitham38140@gmail.com}

$\left.2^{*}\right)$ Mechanical Eng. Dept., AlNahrian University, Baghdad, Iraq.

ansamadil@gmail.com.com

\section{Paper History:}

Received: $30^{\text {th }}$ Oct. 2019

Revised: $8^{\text {th }}$ Dec. 2019

Accepted: $29^{\text {th }}$ Jan. 2020

\begin{abstract}
Forced vibration has been experimentally investigated on a model consists of circular pipe with $1.6 \mathrm{~m}$ length. The pipe built in tank $(1.2 \mathrm{~m}$ length, $0.6 \mathrm{~m}$ height and $0.6 \mathrm{~m}$ width) horizontally at $0.4 \mathrm{~m}$ height with two different diameters $\mathrm{d}=15 \mathrm{~mm}$ and $\mathrm{d}=35 \mathrm{~mm}$. The pipe conveying laminar flow in the fully developed region, of Reynolds number equals 2000. The experimental results of span pipe conveying water at five stations of forced excitation vibration were studied. The harmonic forced vibration with two different excitation frequencies $(10 \mathrm{~Hz}$ and $15 \mathrm{~Hz})$ are imposed at all of the five locations. The distance between two stations is $(0.2 \mathrm{~m})$. Two conditions of pipe environment have been applied, the first in air and the other was immersed in water. It is concluded that the effect of flow induced vibration due to the pipe conveying fluid increases the maximum deflection when the fluid speed increases. The water surrounds the pipes reduce the effect of excitation vibration about $(33-46 \%)$. The effect difference between the excitation frequencies was about (4-7\%).
\end{abstract}

Keywords: Flow Induced Vibration, Fully Developed, Laminar

$$
\begin{aligned}
& \text { التحقيق التجريبي للاهتزاز الناجم عن التدفق للأنبوب داخل الماء }
\end{aligned}
$$

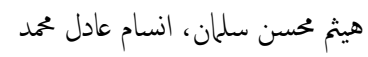

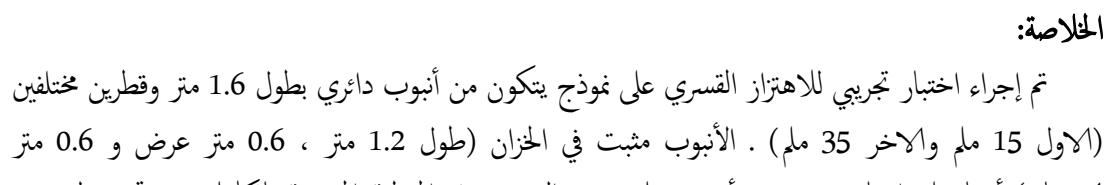

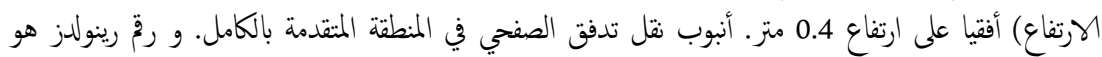

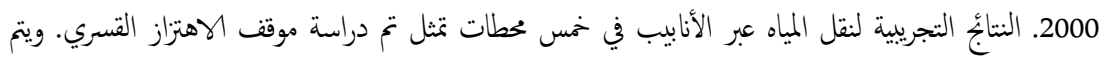

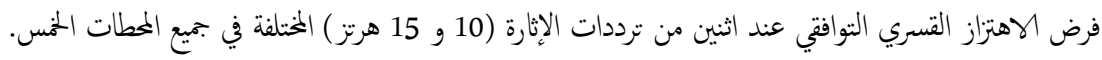

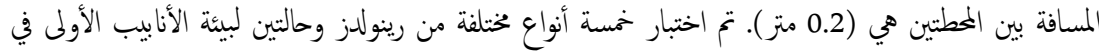

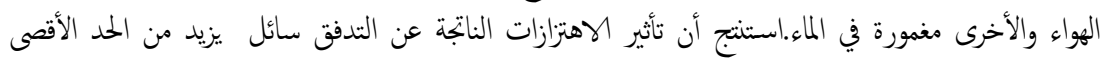

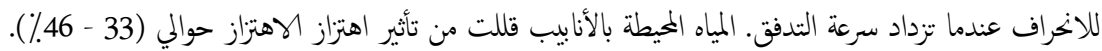

$$
\begin{aligned}
& \text { فرق الثاثير بين تزددات الإثارة حوالي (4 -7.7). }
\end{aligned}
$$

\section{Introduction}

The interactive phenomena between body and fluid motion represent one of the most difficult problems in the field of fluid dynamics. Despite its difficulty, vibration analysis of a pipe vibration has been a subject of numerous investigations due to their wide application in many industrial fields. Many researchers presented studies on modeling and derivation of the equations of motion for pipes conveying fluid. They carried out the vibration and stability analysis of straight or curved pipes subjected to various supports or loading.

In early 1950, the vibration problems uncounted in oil transporting pipes motivated the initial work on the transverse vibration of tube conveying fluid. The study of the dynamics for flexible tubes conveying fluid had begun with an attempt by Ashley, et al. [1], which described the vibrations observed in the Arabian transportation pipeline. They assumed the case of the tube with both ends simply supported. Housner [2] used an approximate power series to find the governing equation but neglected the effect of internal pressure. Noirdson[3] studied the stability of steady flow for simply supported pipe and he found the same conclusions which were made by Ashley et al. [1] and Housner [2], that the natural frequency for a system reduces with the increase in the fluid flow velocity, which lead the system to loss stability by buckling. 
Mohsen, et al. [4] presented an experimental study based on the critical velocities from several measurement of the fundamental natural frequencies. In this study they used two pipe models at three different boundary conditions, low flow-rate pumps and simple fluid circuit. The results showed that the present study is more accurate for calculating the critical velocities of $\mathrm{c}-\mathrm{p}$ and $\mathrm{p}-\mathrm{p}$ pipes. However, for $\mathrm{c}-\mathrm{c}$ pipes it was not so unless a higher flow rate is used

Dayang et al. [5] investigated the Fluid-Structure Interaction (FSI) effect on structural dynamic responses of AP1000 shield building with empty and filled water tanks and to find the optimum height of water level for decreasing seismic response under inputs of earthquake excitations. They used nonlinear FSI algorithm of finite element method based on ANSYS platform in order to compare with the experimental results of structural seismic responses and fluid free vibration. A series of numerical simulations on several partially-filled models in one artificial and six natural earthquakes based on the validated numerical model are carried out and corresponding results, such as displacement and peak acceleration. From results, the partially-filled shield building appears great FSI effect, which lead to significant influence on structural dynamic characteristics and responses. Reasonable design of the water level can contribute to decreasing structural responses and improving seismic safety.

Hongjun et al. [6] performed an experiment in a water-air loop to investigate the internal slug flow induced vibration of a free and flexible vertical pipe with aspect ratio of 158 . They used high speed imaging method to record the vibration displacements of the model and the flow regime of two-phase mixture in the pipe simultaneously. The results showed that an in-plane vibration is created by the internal slug flow, and the responses along the two directions in the plane are interdependent to each other. In the considered liquid-gas ratio the second mode dominates the response. The hydrodynamic behaviors of slug flow, including the liquid-gas ratio, liquid slug length and superficial velocity, affect the local pressure fluctuation and consequently influence the amplitude.

Sally et al. [7] presented an experimental study of self-induced vibrations produced by vibrating heat pipe. The vibrating heat pipe was mounted in top heating mode from elastic strands into an ice bath with three single-axis accelerometers. The results showed that the strongest accelerations are produced in the same axis as the primary path of fluid travel through the channels. An initial peak acceleration that corresponds with oscillating heat pipe startup was also observed. Additionally, asymmetry in the vertical axis suggests a possible imbalance between the evaporator and condenser sections. Oscillating heat pipe geometry likely plays a significant role on the resulting vibrations, and therefore future research should explore different device designs and configurations.

Khot et al. [8] studied the effect of pipe conveying turbulent flow parameters such as volumetric flow rate, pipe wall thickness, and diameter on the amplitude of pipe vibration in straight pipe experimentally, analytically and by simulation method to find the effect of the parameters on the pipe. DOE technique was used to know the effect of each factor i.e. pipe thickness, diameter and discharge on vibrational amplitude. It is observed that the amplitude of vibration reduces with when volumetric flow rate reduces.

Soe et al. [9] calculated the frequency by analysis of a system under a sinusoidal force. Using light plastic pipes of three materials (Polystyrene, Acrylic and HMWPE) and sound waves, resonance phenomena was demonstrated. They used two different transducers to record the vibration of materials, piezoelectric accelerometer and electret condenser microphone. For accelerometer the expected values for Acrylic, Polystyrene, HMWPE1, and HMWPE2 were $3.79,12.52,5.91$, and $6.36 \mathrm{HZ}$ respectively.

Lee et al. [10] presented a new non-linear model of a straight tube contains flowing fluid for vibration analysis when both ends of the tube were fixed. Using the non-linear Lagrange strain theory and the Euler-Bernoulli beam theory, for extended Hamilton's principle the coupled non-linear relations of motion for the transverse and longitudinal displacements were derived. These relations of motion were discretized by using the Galerkin method. After that linearized the discretized relations in the neighborhoods of the equilibrium position, the natural frequencies were determined from the linearized equations. On the other hand, the time histories for the displacements were also obtained by applying the generalized time integration method to the non-linear discretized equations.

Wang, et al. [11] studied the dynamic and static disturbances of tilted and submerged concentric pipes containing flowing fluid. For inner tubular beam, the governing equation was derived under small deformation assumption. It detected the discretized dynamical equations using spatial finite- difference schemes. In the case of steady flow, both flutter and buckling disturbances were investigated.

\section{Objectives}

-Modeling and constructing an experimental rig to study the effects of the flowing factors on FIV in the fully developed flow region of a pipe conveying water:

- Reynolds number (2000).

-Excitation frequency (10 and $15 \mathrm{~Hz}$ ).

-The harmonic forced vibration imposed at five locations on pipe. The distance between two locations is $(200 \mathrm{~mm})$.

- Pipe dimeter (15mm and $35 \mathrm{~mm}$ ).

-Two conditions of pipe environment; the first is the air and the other is the water in order to compare and discuss the above results and present general conclusions.

\section{Experimental Setup}

An experimental rig was designed and constructed at al-Nahrain University / college of 
engineering mechanical department Lab. Sketch of the experimental model is shown in Fig (1). The model consists of an Acrylic tank (1.22 x0.6x0.6) m and Acrylic pipe length $(1.6 \mathrm{~m})$ with inner diameters $(15 \mathrm{~mm}$ and $35 \mathrm{~mm})$ and outer diameters $(20 \mathrm{~mm}$ and $40 \mathrm{~mm})$. The pipes built-in with the tank at $0.4 \mathrm{~m}$ height.

Fig.(2) shows the water circuit which consist of a tank of water supply, pump, PVC valve and flow meter.

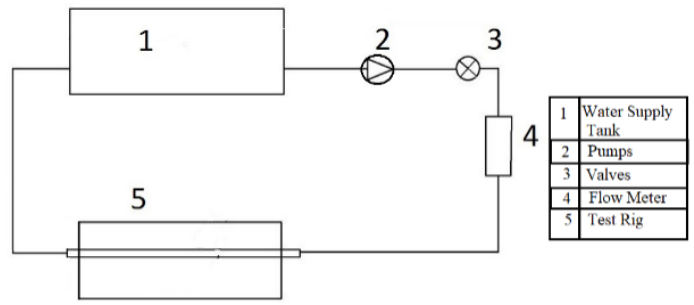

Figure (2): Schematic diagram of the water circuit used in the vibration test.

Fig.(3) shows the diagram of the instrument used to generate excitation frequency which consist of function (sine) generator, power amplifier and vibration exciter.

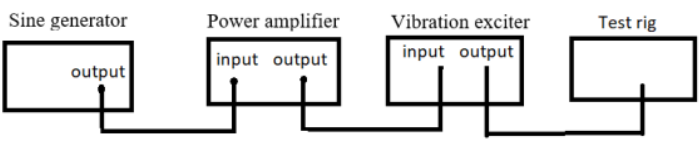

Figure (3): Electrical circuit used to generate excitation frequency.

The response of the model was recorded by 4533-B accelerometer and displayed on UT3025C oscilloscope through a charge amplifier as shown in Fig.(4).

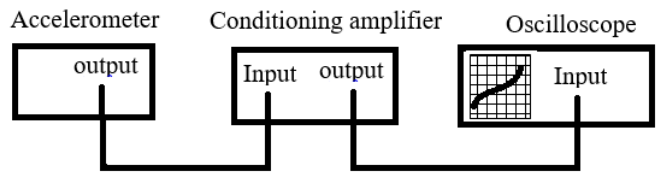

Figure (4): Electrical circuit used for acceleration measurement.

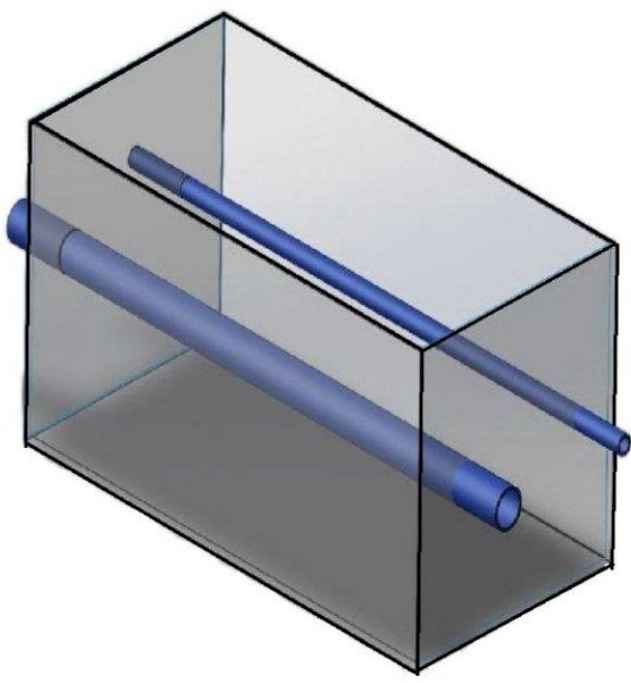

Top View

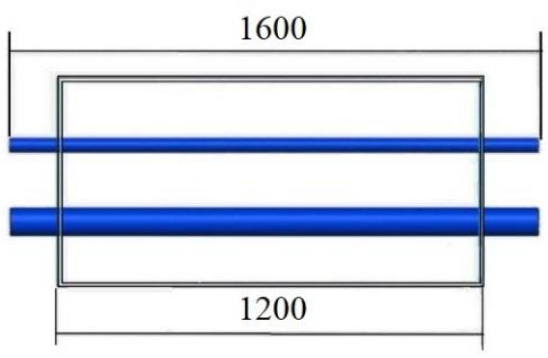

Front View

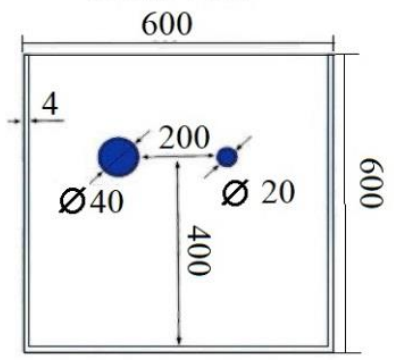

All dimensions are in $\mathrm{mm}$

Figure (1): Schematic diagram of the experimental model 
The equipment used in the vibration test are:

1-Function Generator GFG-8015G.

2-Power amplifier B\&K 2719.

3-PMvibration exciter B\&K 4808.

4-Accelerometer type B\&K 4533-B.

5-Conditioning amplifier type B\&K 2692-A.

6-Digital Storage Oscilloscope UNI-T

UT3025C.

As shown in Fig.(5).

\section{Assumptions:}

1-The flow is laminar.

2-Fully developed flow.

\section{$\mathrm{X} / \mathrm{D}=0.05 \mathrm{Re}_{\mathrm{D}}$}

Where $\mathrm{X}$ is the minimum length required to fulfil a fully developed flow as shown in Fig (7).

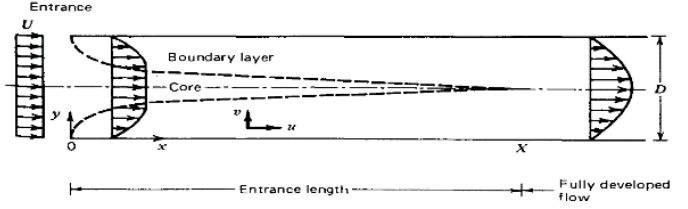

Figure (7): Developing flow in the entrance region of pipe [12].

3-Incompressible flow.

4-Neglect the losses in connection cables.

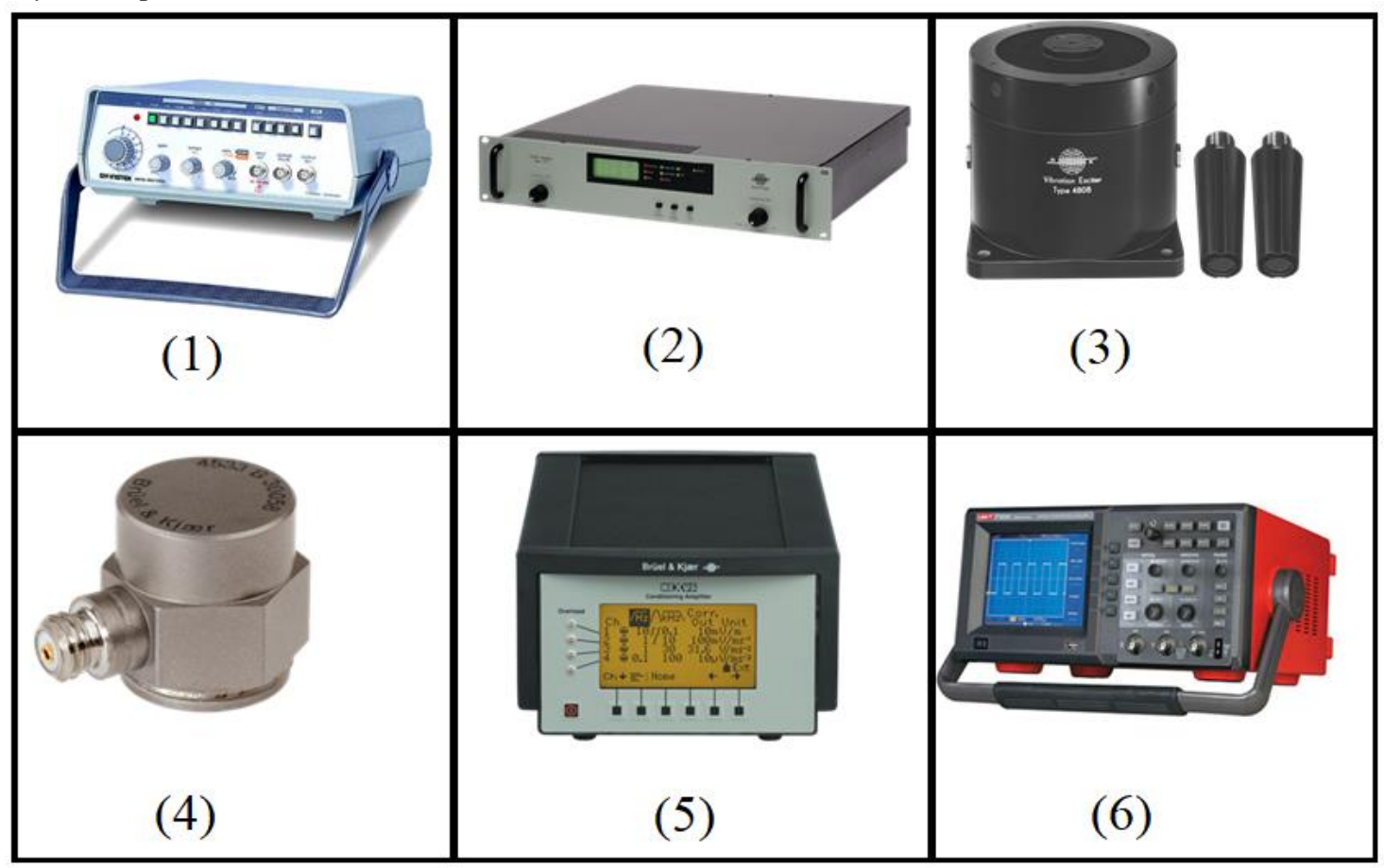

Figure (5): The equipment used in the vibration test.

Photograph for the experimental setup, is shown in Fig (6).

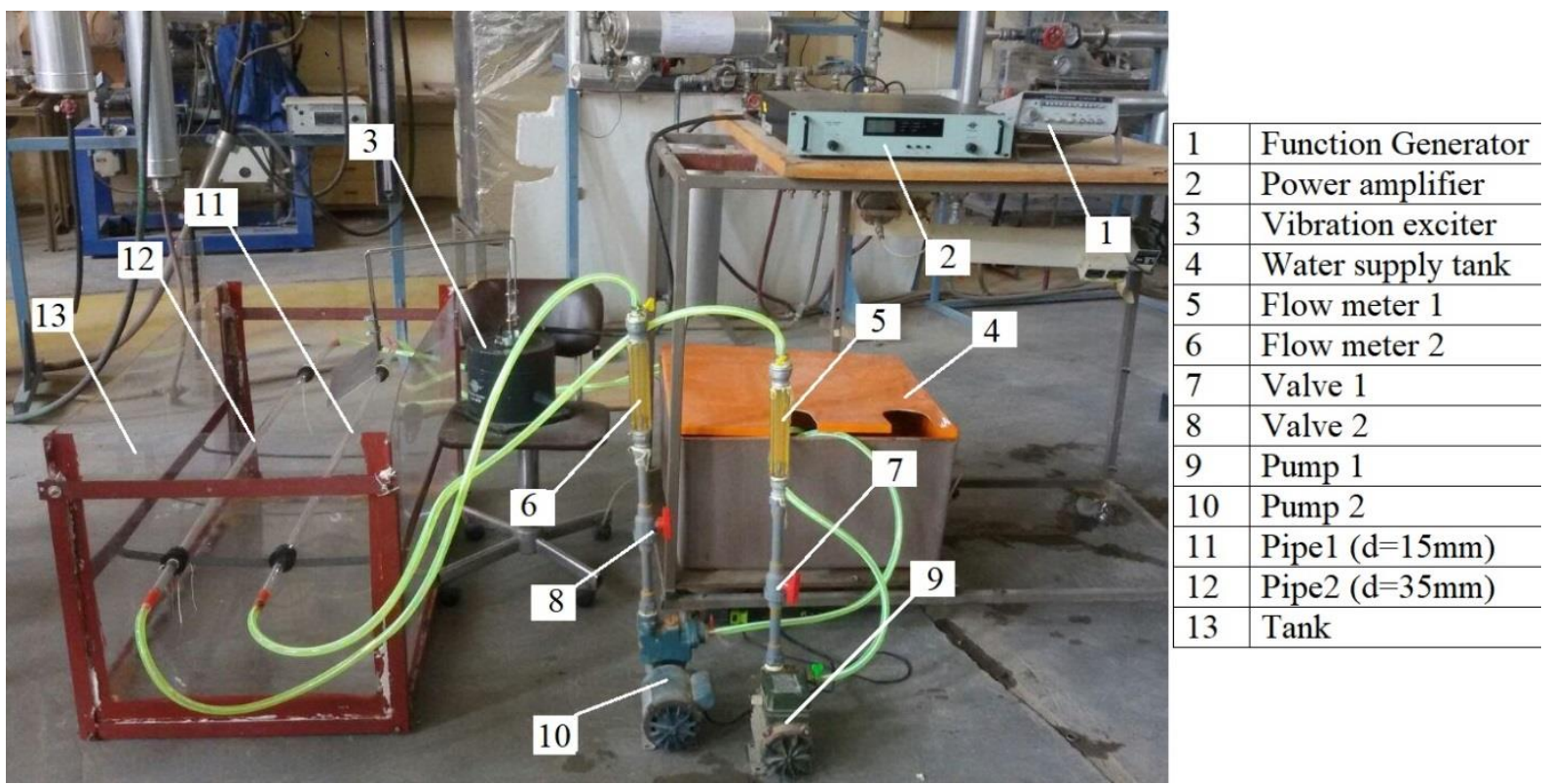

Figure (6): Set-up for vibration test. 


\section{Experimental Procedure:}

To carry out the experiments, the following procedure was followed:

1. The water circuit is connected (see Fig. 2) then fill water supply tank and the flow meter must be in vertical position.

2. The excitation circuit is connected (see Fig. 3) then connect the shaker with test pipe directly by U-shape rod.

3. The measurement circuit is connected (see Fig. 4) then connect the accelerometer with test pipe directly by adhesive.

4. The shaker and the accelerometer are placed at $200 \mathrm{~mm}$ of pipe length the turn on all the instruments and equipment used then by the function generator select excitation frequency $15 \mathrm{~Hz}$ and sinusoidal wave type.

5. Turn on the pump and control the flow rate in order to make Reynolds number equal 2000 and record the measurement.

6. Same steps 4 and 5 were recurred but taking new excitation frequency $10 \mathrm{~Hz}$.

7. Same steps from 4 to 6 were recurred but putting the accelerometer at $400 \mathrm{~mm}$ of pipe length.

8. Same steps from 4 to 6 were recurred but putting the accelerometer at $600 \mathrm{~mm}$ of pipe length.

9. Same steps from 4 to 6 were recurred but putting the accelerometer at $800 \mathrm{~mm}$ of pipe length.

10. Same steps from 4 to 6 were recurred but putting the accelerometer at $1000 \mathrm{~mm}$ of pipe length.

11. Same steps from 4 to 10 were recurred but putting the shaker at $400 \mathrm{~mm}$ of pipe length.

12. Same steps from 4 to 10 were recurred but putting the shaker at $600 \mathrm{~mm}$ of pipe length

13. Same steps from 4 to 10 were recurred but putting the shaker at $800 \mathrm{~mm}$ of pipe length

14. Same steps from 4 to 10 were recurred but putting the shaker at $1000 \mathrm{~mm}$ of pipe length

15. Same steps from 4 to 14 were recurred but the rig tank filled with water at $0.45 \mathrm{~m}$ height

16. Same steps from 4 to 15 were recurred but taking new pipe diameter $(\mathrm{d}=35 \mathrm{~mm})$.

\section{Results and Discussion:}

Forced vibration has been experimentally investigated for laminar water flow in the fully developed region of span pipe with fixed ends. The results have been made and discussed the effects of the various parameters.

Figures (8) to (12) show diagrams of the deflection of pipe conveying water without restriction with the pipe length at $\operatorname{Re}=2000, f=15 \mathrm{~Hz}$, two different diameters and two different surrounding conditions. First air and the other immersed in water. The curves were turn of normally affected by the forced vibration. Figures (8-12) show the results of placing the vibration exciter at 200, 400,600, 800 and $1000 \mathrm{~mm}$ of pipe length respectively.

Figures (13) to (17) show diagrams of the deflection of pipe conveying water without restriction with the pipe length at $\operatorname{Re}=2000, f=10 \mathrm{~Hz}$, two different diameters and two different surrounding conditions. First air and the other immersed in water. The curves were turn of normally affected by the forced vibration. Figures (13-17) show results of placing the vibration exciter at 200, 400,600, 800 and $1000 \mathrm{~mm}$ of pipe length respectively.

The effect of flow induced vibration due to the pipe conveying fluid increases the maximum deflection when the fluid speed increased as shown in Fig (18). The water surrounds the pipes reduced the effect of excitation vibration about $33.75 \%$ and $34.6 \%$ for pipe $(\mathrm{d}=15 \mathrm{~mm})$ under $15 \mathrm{~Hz}$ and $10 \mathrm{~Hz}$ excitation frequencies respectively. The water surrounds the pipes reduced the effect of excitation vibration about $43.39 \%$ and $44.3 \%$ for pipe $(\mathrm{d}=35 \mathrm{~mm})$ under $15 \mathrm{~Hz}$ and $10 \mathrm{~Hz}$ excitation frequencies respectively.

The difference effect between the excitation frequencies is about $(4.69-6.41 \%)$.

It can be noticed from Fig (19) that the present work trend as previous work [13]; specifically they indicate that the deflection increases when the excitation frequency increased and the maximum deflection occurs at the same point of the excitation applied on the pipe.

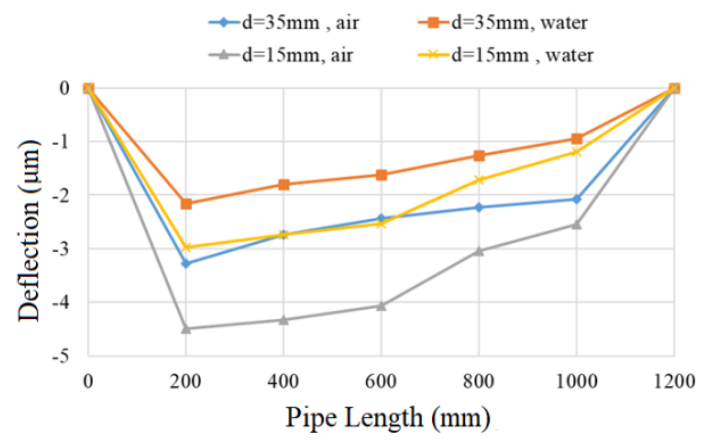

Figure (8): Comparison of results of vibration exciter placed at point $200 \mathrm{~mm}$ of pipe length, $f=15$ $\mathrm{Hz}$ and $\mathrm{Re}=2000$.

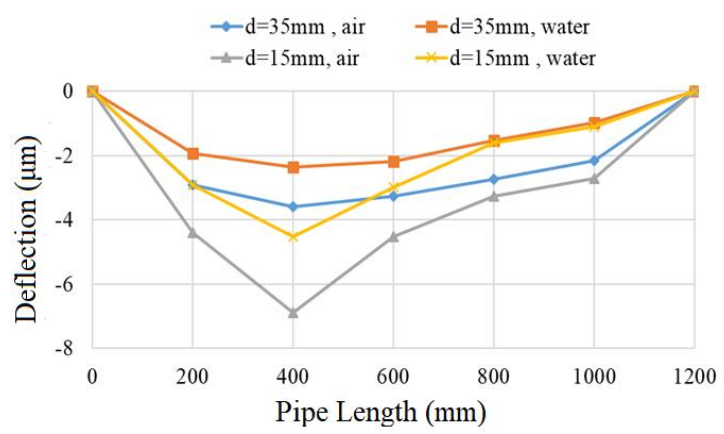

Figure (9): Comparison of results of vibration exciter placed at point $400 \mathrm{~mm}$ of pipe length, $f=15$ $\mathrm{Hz}$ and $\mathrm{Re}=2000$.

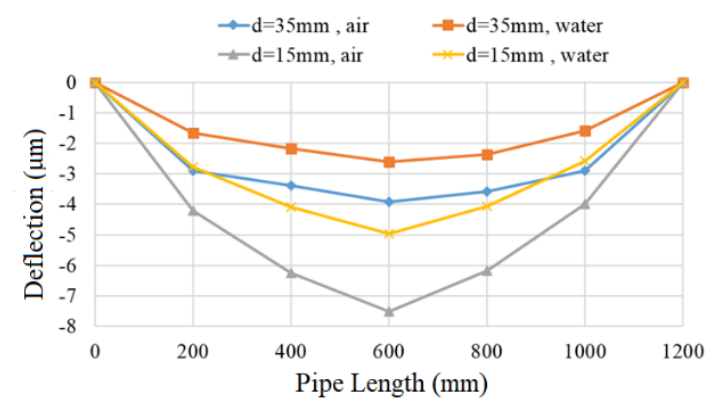


Figure (10): Comparison of results of vibration exciter placed at point $600 \mathrm{~mm}$ of pipe length, $f=15$ $\mathrm{Hz}$ and $\mathrm{Re}=2000$.

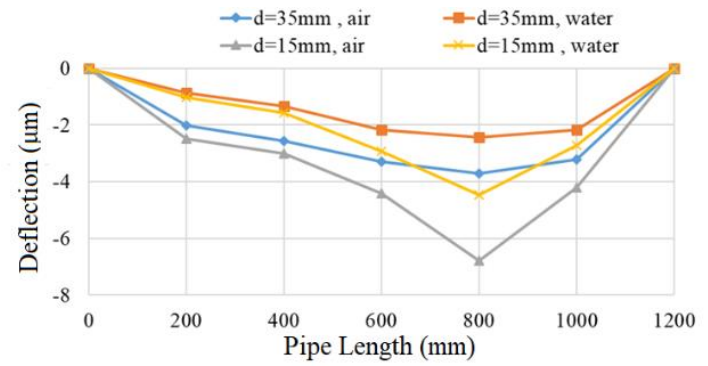

Figure (11): Comparison of results of vibration exciter placed at point $800 \mathrm{~mm}$ of pipe length, $f=15$ $\mathrm{Hz}$ and $\mathrm{Re}=2000$.

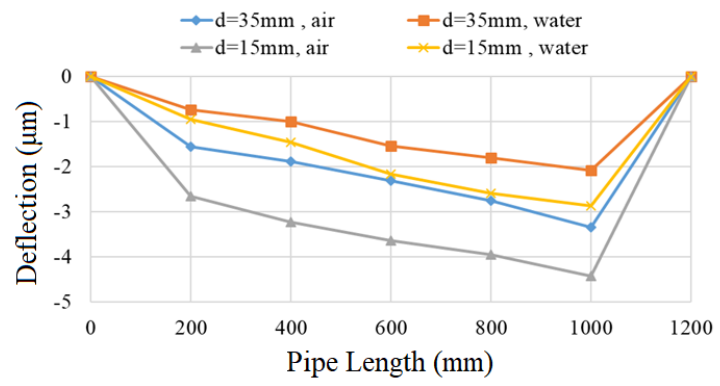

Figure (12): Comparison of results of vibration exciter placed at point $1000 \mathrm{~mm}$ of pipe length, $f$ $=15 \mathrm{~Hz}$ and $\mathrm{Re}=2000$.

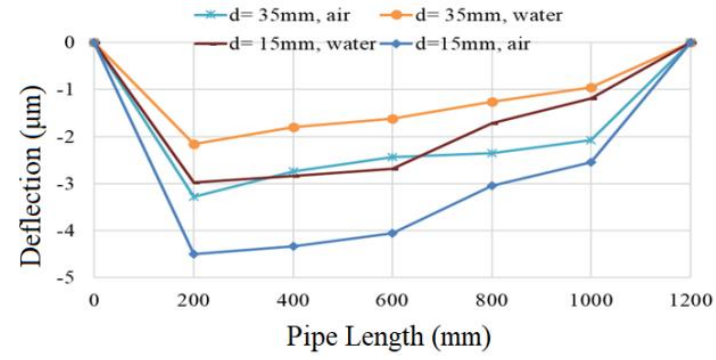

Figure (13): Comparison of results of vibration exciter placed at point $200 \mathrm{~mm}$ of pipe length, $f=10$ $\mathrm{Hz}$ and $\mathrm{Re}=2000$.

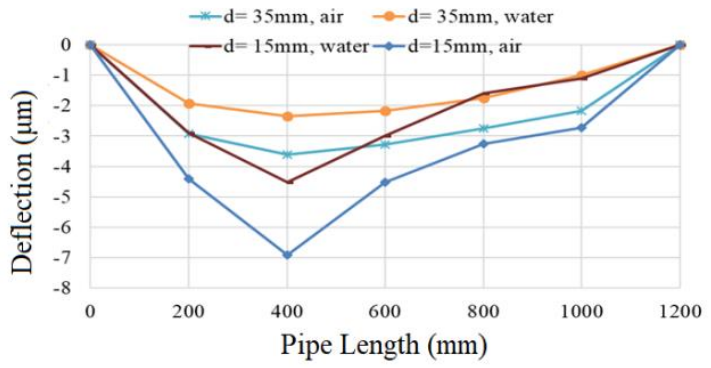

Figure (14): Comparison of results of vibration exciter placed at point $400 \mathrm{~mm}$ of pipe length, $f=10$ $\mathrm{Hz}$ and $\mathrm{Re}=2000$.

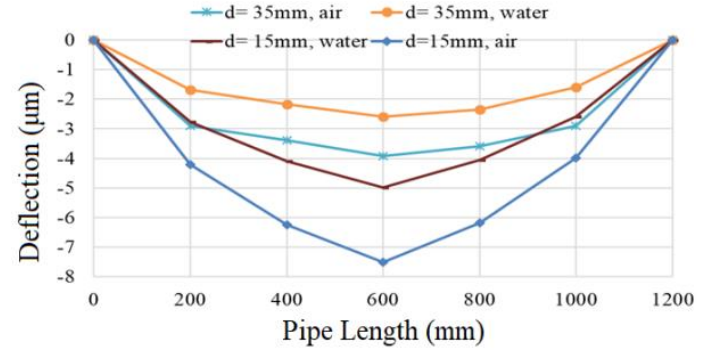

Figure (15): Comparison of results of vibration exciter placed at point $600 \mathrm{~mm}$ of pipe length, $f=10$ $\mathrm{Hz}$ and $\mathrm{Re}=2000$.

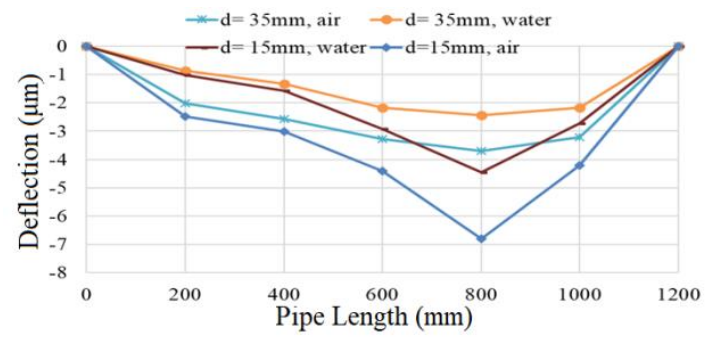

Figure (16): Comparison of results of vibration exciter placed at point $800 \mathrm{~mm}$ of pipe length, $f=10$ $\mathrm{Hz}$ and $\mathrm{Re}=2000$.

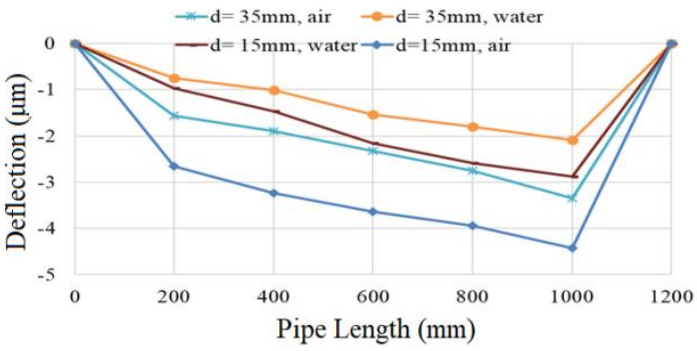

Figure (17): Comparison of results of vibration exciter placed at point $1000 \mathrm{~mm}$ of pipe length, $f$ $=10 \mathrm{~Hz}$ and $\mathrm{Re}=2000$.

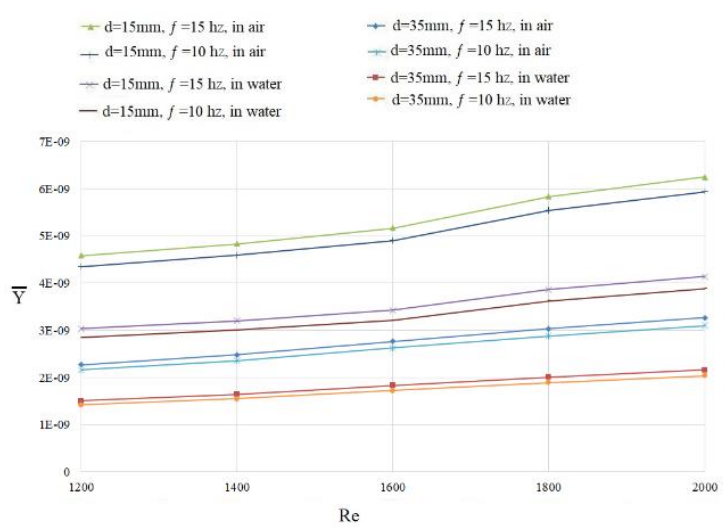

Figure (18): Deflection per pipe length diagram with Reynolds numbers. 


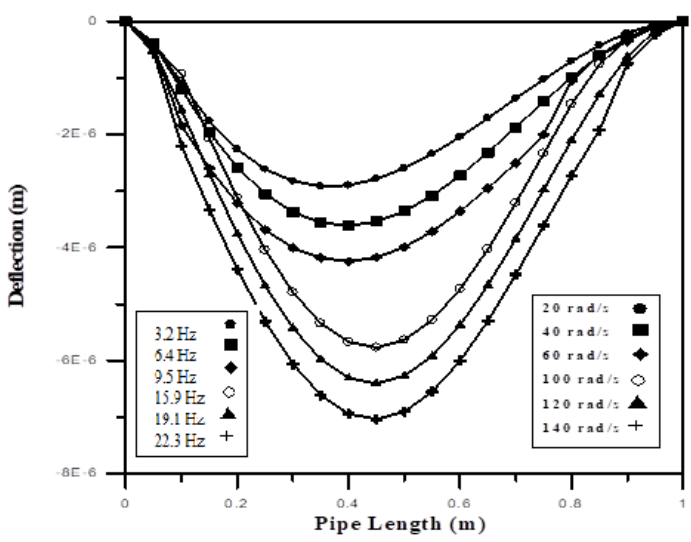

Figure (19): Deflection diagram with pipe length, vibration exciter placed at point $500 \mathrm{~mm}$ of pipe length [13]

\section{Conclusions:}

From the results obtained, the following conclusions can be deduced:-

1-The effects of flow induced vibration due to the pipe conveying fluid increases the maximum deflection when the fluid speed increases.

2-The water surround the pipes reduced the effect of excitation vibration about $(33.75-44.3 \%)$.

3-The effect difference between the excitation frequencies is about $(4.69-6.41 \%)$.

4-The pipes conveying fluid dynamics was examined utilizing the Tiomoshenko beam theory. So, this is a simply enough extension of previous theory, solution in the equations of motion necessitated the use of a fairly treatments of the variation principle, which proved to the powerful and efficient analytical tool.

\section{References:}

[1] H. Ashley \& G. Havilland, "Bending Vibrations of a Pipe Line Containing Flowing Fluid ", Journal of Applied Mechanic, Vol.17, pp.229-232, 1950.

[2] G. W. Housner, "Bending Vibrations of a Pipe Line Containing Flowing fluid ", Journal of Applied Mechanic, Vol.19, pp.205-208, 1952

[3] F. I. N. Niordson, "Vibrations of a Cylindrical Tube Containing Flowing Fluid", K. Tek. Högsk. Handl, No.2, 1953
[4] Mohsen J. Jweeg, Albert E. Yousif and Mahmud R. Ismail" Experimental Estimation of Critical Buckling Velocities for Conservative Pipes Conveying Fluid" Al-Khwarizmi Engineering Journal, Vol. 7, No.4, PP 17 -26 (2011)

[5] Hongjun Zhu, Yue Gao and Honglei Zhao "Experimental investigation on the flow-induced vibration of a free-hanging flexible riser by internal unstable hydrodynamic slug flow" Ocean Engineering, Volume 164, Pages 488-507. 2018

[6] Dayang Wang, Chengqing Wu and Wencheng Huang, "Vibration investigation on fluid-structure interaction of AP1000 shield building subjected to multi earthquake excitations" Annals of Nuclear Energy 126:312-329 · January 2019

[7] Sally M. Smith, Matthew J. Rhodes, Brent S. Taft, and Emil V. Ardelean. "Experimental Investigation of Flow-Induced Vibrations of an Oscillating Heat Pipe", Journal of Thermophysics and Heat Transfer, Vol. 31, pp. 871-877. https://doi.org/10.2514/1.T5020,2017

[8] S. M. Khot, P. Khaire and Abhishek S. Naik "Experimental and simulation study of flow induced vibration through straight pipes" International Conference on Nascent Technologies in Engineering (ICNTE) ieeexplore.ieee.org/abstract/document/7947938 ,2017

[9] Y. Soe, G. Bethany, and P. Robert, "Vibration Analysis of a Sinusoidally Driven System" University of Pennsylvania, www.seas.upenn.edu, 1997

[10] S. I. Lee and J. Chung "New Non-Linear Modelling for Vibration Analysis of a Straight Pipe Conveying Fluid" Journal of Sound and Vibration, Vol.254, No.2, pp. 313-325, 2002.

[11] X. Wang and F. Bloom "Stability Issues of Concentric Pipes Containing Steady and Pulsatile Flows" Journal of Fluids and Structures, Vol.17, pp.1-16, 2001.

[12] Adrian Bejan "Convection Heat Transfer" 3rd edition, 2004

[13] Ansam A. Mohammed "The Effect of Induced Vibration on the Flow Properties in a Pipe Fitted with an Orifice", Ph.D. Thesis, Al-Nahrain University, 2006. 